\title{
Emergency peripartum hysterectomy in a tertiary hospital in Upper Egypt: six years analysis
}

\author{
Ahmed M. Abbas ${ }^{1 *}$, Ahmed Y. Abdelbadee ${ }^{1}$, Mariam T. Amin', Reham M. Abdelrahman ${ }^{3}$, \\ Sara M. Tolba ${ }^{3}$, Ahmed R. Abdelkarim ${ }^{3}$, Ahmed Y. Shahin ${ }^{1}$, Safwat A. Salman ${ }^{1}$
}

\author{
${ }^{1}$ Department of Obstetrics and Gynecology, Faculty of Medicine, Assiut University, Egypt \\ ${ }^{2}$ Department of Public Health, Faculty of Medicine, Assiut University, Egypt \\ ${ }^{3}$ Assiut University Hospital, Faculty of Medicine; Assiut University, Egypt
}

Received: 15 February 2016

Accepted: 11 March 2016

\section{*Correspondence:}

Dr. Ahmed M. Abbas,

E-mail: bmr90@hotmail.com

Copyright: (C) the author(s), publisher and licensee Medip Academy. This is an open-access article distributed under the terms of the Creative Commons Attribution Non-Commercial License, which permits unrestricted non-commercial use, distribution, and reproduction in any medium, provided the original work is properly cited.

\begin{abstract}
Background: Emergency peripartum hysterectomy (EPH) is often performed for life-threatening obstetric conditions especially when conservative treatment approach fails to stop postpartum hemorrhage. The aim of the study is to detect the incidence, indications, and complications of EPH over 6 years in Assiut Women Health Hospital in Upper Egypt.

Methods: A historical cohort study conducted between January 2009 and December 2014. Detailed review of all files of cases of EPH including maternal age, parity, gestational age, type of delivery, indications for EPH and outcome of the hysterectomy.

Results: The overall incidence of EPH was 1.30 per 1,000 deliveries. The main indications for hysterectomies were uterine atony $60(48.78 \%)$, abnormal placentation $27(21.95 \%)$ and rupture uterus $25(20.32 \%)$. There were 48 $(39.02 \%)$ maternal deaths, while the perinatal mortality was $20.32 \%$ (25 cases). Using multivariate logistic regression analysis, we found that woman's age $\geq 40$ years and parity $\geq 5$ were the most significant independent predictors for maternal mortality in cases of EPH (OR 5.49; 95\% CI 2.16 - 13.96) and (OR 0.34; 95\% CI 0.15 - 0.77) respectively. Conclusions: The incidence of EPH in Upper Egypt is high. Uterine atony is the major indication for EPH in our hospital. Late referral and delayed decisions to perform hysterectomy contributes in the high mortality rate.
\end{abstract}

Keywords: Peripartum hysterectomy, Uterine atony, Maternal mortality, Postpartum hemorrhage

\section{INTRODUCTION}

Postpartum hemorrhage (PPH) is considered the leading cause of maternal mortality and morbidity in developing countries contributing to $25 \%$ of direct maternal deaths. ${ }^{1,2}$ Conservative treatment of postpartum hemorrhage includes uterine massage, uterotonics (oxytocin, ergotamine), uterine packing, uterine artery embolization, pelvic vessel ligation, B-Lynch suture, multiple square sutures and recombinant activated factor VII. ${ }^{3}$

Emergency peripartum hysterectomy (EPH) is often performed for life-threatening obstetric conditions especially when conservative treatment approach fails to stop postpartum hemorrhage. ${ }^{4}$ The surgery itself can be associated with severe hemorrhage, risk of blood transfusion, intraoperative complications and a high maternal mortality and morbidity risk. ${ }^{5}$

Previous studies in the literature have reported the incidence of EPH varies from 0.29 to 5.09 per 1000 deliveries. $^{6-8}$ Indications for peripartum hysterectomy have changed throughout the years. In the past, the major indications for EPH were uterine rupture and atony. ${ }^{9,10}$ However, recent studies have listed abnormal placentation (placenta previa and placenta accreta) as the 
leading cause of peripartum hysterectomy. ${ }^{11}$ The increase in the cesarean section (CS) rate is the leading cause to an increase in the rate of abnormal placentation, which in turn gives rise to an increase in peripartum hysterectomy rate. $^{12,13}$

Despite the importance of EPH, there is limited number of reports on the outcomes from developing countries. ${ }^{14,15}$ In the current study, we reported on the incidence, indications, outcomes and complications of emergency peripartum hysterectomy performed in a tertiary care hospital in Upper Egypt over a 6-year period.

\section{METHODS}

This is a historical cohort study conducted at Assiut Women Health Hospital, which is the largest maternal tertiary care hospital in Upper Egypt providing health services for seven governorates. The study included patients who received care from January 2009 till December 2014. The Ethical Review Board of Assiut Faculty of medicine approved the study.

The data were collected from the patients' files by the authors (R.M., A.R. and S.M.). Information obtained from the medical records included maternal age, gravidity, parity, gestational age, types of delivery and indications of EPH. Emergency peripartum hysterectomy was defined as a hysterectomy performed for hemorrhage unresponsive to other treatment within 24 hours of delivery. ${ }^{12}$ The type of hysterectomy, intraoperative complications, postoperative complications, preoperative and postoperative haemoglobin levels, amount of blood transfused, the length of stay in days at the hospital and admission to intensive care unit were recorded. The main complications included massive hemorrhage, infection, disseminated intravascular coagulopathy (DIC), urinary bladder injury, renal failure, multiorgan failure and wound dehiscence. Peripartum maternal and fetal complications such as fetal mortality and causes of maternal mortality were evaluated. The total number of deliveries during the same period was also determined.

Analysis of data was done using SPSS Inc., (Statistical Program for Social Science Inc.,) Chicago, IL, USA, version 21. Qualitative variables were expressed as frequency and percentage. Chi-square test was used to compare qualitative variables. Quantitative variables were presented in terms of mean \pm standard deviation. For quantitative data, comparison between two groups was done using Student's T-test. Level of significance "P" value was evaluated, where $\mathrm{P}$ value $<0.05$ was considered statistically significant. Multivariable logistic regression analysis was done to identify independent risk factors for maternal mortality in cases underwent EPH.

\section{RESULTS}

During a 6-year study period, a total of 94196 pregnant women delivered in our hospital; 51228 (54.38\%) of them delivered vaginally and 42968 (45.62\%) by cesarean section. One hundred twenty-three EPH were performed during this time period. The incidence was 1.30 per 1,000 deliveries.

The mean age of EPH cases was $30.12 \pm 6.04$ years and mean gravidity was $5.23 \pm 2.72$. There were four primiparous (3.25\%), while $119 \quad(96.75 \%)$ were multiparous women. All primparas who underwent EPH were due to uterine atony $(100 \%)$. The mean gestational age at delivery was $36.5 \pm 2.3$ weeks (range 24-41 weeks) (Table 1).

Table 1: Demographic and clinical characteristics of emergency peripartum hysterectomy cases.

\begin{tabular}{|ll|}
\hline Characteristics & Mean \pm SD (range), $n(\%)$ \\
\hline Age (years) & $30.12 \pm 6.04(18-44)$ \\
\hline Age groups & $7(5.69)$ \\
\hline$<20$ & $49(39.84)$ \\
$20-29$ & $52(42.28)$ \\
$30-39$ & $15(12.19)$ \\
\hline$\geq 40$ & $5.23 \pm 2.72(0-10)$ \\
\hline Gravidity & $4(3.25)$ \\
\hline Parity & $54(43.90)$ \\
\hline Primipara & $65(52.85)$ \\
\hline P 1-4 & $68(55.28)$ \\
\hline$\geq$ P 5 & $51(41.46)$ \\
\hline Previous cesarean delivery & $72(58.54)$ \\
\hline Mode of delivery & $36.5 \pm 2.3(24-41)$ \\
\hline Vaginal & \\
\hline Cesarean & $60(48.78)$ \\
\hline $\begin{array}{l}\text { Gestational age at delivery } \\
\text { (weeks) }\end{array}$ & $27(21.95)$ \\
\hline Indications of hysterectomy & \\
\hline Uterine atony & $25(20.32)$ \\
\hline Abnormal Placentation & $2(1.63)$ \\
\hline Rupture uterus & $9(7.32)$ \\
\hline Placental abruption & $71(57.72)$ \\
\hline Others & $52(42.28)$ \\
\hline Type of hysterectomy & \\
\hline Supracervical & \\
\hline Total & \\
\hline $\begin{array}{l}\text { Duration of hysterectomy } \\
\text { (minutes) }\end{array}$ & \\
\hline $\begin{array}{l}\text { Duration of hospital stay } \\
\text { (days) }\end{array}$ & \\
\hline
\end{tabular}

Hysterectomies were performed in 51 (41.46\%) cases after vaginal delivery (1/1000 vaginal delivery) and 72 (58.54\%) cases during or after CS (1.68/1000 cesarean section). Of the 72 cesarean hysterectomies, $58(80.56 \%)$ were performed at the same time of CS. In the remaining $14(19.44 \%)$ patients, hysterectomy was performed after completion of CS.

The main indications for hysterectomy were uterine atony $(48.78 \%)$, abnormal placentation $(21.95 \%)$ and uterine 
rupture $(20.32 \%)$ of cases. Other causes included placental abruption, uterine infections and traumatic injuries during CS. All hysterectomies were performed by a consultant obstetrician. The mean duration of the peripartum hysterectomy was $139.22 \pm 75.3$ minutes.

Table 2: Comparison of demographic and clinical characteristics of surviving and mortality cases.

\begin{tabular}{|c|c|c|c|c|}
\hline & & Surviving cases $(\mathrm{n}=75)$ & Mortality cases $(n=48)$ & p-value \\
\hline Age* & & $30.7 \pm 5.7$ & $29.9 \pm 7.3$ & 0.515 \\
\hline Gravidity* & & $5.4 \pm 2.5$ & $4.7 \pm 2.9$ & 0.123 \\
\hline \multicolumn{5}{|c|}{ Outcome of previous pregnancies } \\
\hline Living children* & & $4.1 \pm 2.2$ & $3.2 \pm 2.2$ & 0.421 \\
\hline Abortion* & & $0.40 \pm 0.69$ & $0.48 \pm 1.2$ & 0.660 \\
\hline \multicolumn{5}{|l|}{ Current pregnancy } \\
\hline Number of fetuses & Singleton & $73(97.3 \%)$ & $47(97.9 \%)$ & \multirow[t]{2}{*}{0.838} \\
\hline & Multiple & $2(2.7 \%)$ & $1(2.1 \%)$ & \\
\hline \multirow[t]{2}{*}{ Gestational age at delivery } & $\leq 28$ weeks & $3(4 \%)$ & $3(6.3 \%)$ & \multirow[t]{2}{*}{0.572} \\
\hline & $>28$ weeks & $72(96 \%)$ & $45(93.7 \%)$ & \\
\hline Perinatal mortality & $13(17.3 \%)$ & $13(17.3 \%)$ & $12(25 \%)$ & 0.303 \\
\hline \multirow[t]{4}{*}{ Mode of delivery } & $\begin{array}{l}\text { Spontaneous } \\
\text { vaginal }\end{array}$ & $27(36 \%)$ & $20(41.7 \%)$ & \multirow[t]{4}{*}{0.842} \\
\hline & $\begin{array}{l}\text { Operative } \\
\text { vaginal }\end{array}$ & $2(2.7 \%)$ & $2(4.1 \%)$ & \\
\hline & $\begin{array}{l}\text { Planned } \\
\text { cesarean }\end{array}$ & $18(24 \%)$ & $8(16.7 \%)$ & \\
\hline & $\begin{array}{l}\text { Emergency } \\
\text { cesarean }\end{array}$ & $28(37.4 \%)$ & $18(37.4 \%)$ & \\
\hline \multirow[t]{5}{*}{ Indications of hysterectomy } & Uterine atony & $29(38.7 \%)$ & $31(64.6 \%)$ & \multirow[t]{5}{*}{0.011} \\
\hline & $\begin{array}{l}\text { Abnormal } \\
\text { Placentation }\end{array}$ & $24(32 \%)$ & $3(6.2 \%)$ & \\
\hline & $\begin{array}{l}\text { Rupture } \\
\text { uterus }\end{array}$ & $17(22.7 \%)$ & $8(16.7 \%)$ & \\
\hline & $\begin{array}{l}\text { Placental } \\
\text { abruption }\end{array}$ & $1(1.3 \%)$ & $1(2.1 \%)$ & \\
\hline & Others & $4(5.3 \%)$ & $5(10.4 \%)$ & \\
\hline \multirow[t]{2}{*}{ Type of hysterectomy } & Total & $30(40 \%)$ & $22(45.8 \%)$ & \multirow[t]{2}{*}{0.610} \\
\hline & Supracervical & $45(60 \%)$ & $26(54.1 \%)$ & \\
\hline Hospital stay (days)* & & $9.8 \pm 10.8$ & $7.7 \pm 9.4$ & 0.273 \\
\hline $\begin{array}{l}\text { Blood products } \\
\text { transfusion(units) }\end{array}$ & & $10.4 \pm 6.9$ & $14.9 \pm 11.7$ & 0.013 \\
\hline
\end{tabular}

*Data presented as mean \pm standard deviation

Supracervical hysterectomy was performed in 71 $(57.72 \%)$ cases and total abdominal hysterectomy in 52 $(42.28 \%)$ cases. Majority of Supracervical hysterectomies were done for uterine atony, while total hysterectomies were done mostly in morbidly adherent placenta and ruptured uterus. Unilateral Salpingoophorectomy was performed in $11(8.94 \%)$.

There were $48(39.02 \%)$ maternal deaths, while the perinatal mortality was $20.32 \%$ ( 25 cases). The causes of maternal deaths were irreversible hypovolemic shock (34 cases), DIC (5 cases), pulmonary embolism (4 cases), multiorgan failure ( 3 cases) and 2 cases from acute renal failure. The mean duration of hospital stay for the dead women was $7.7 \pm 9.4$ days, while for the surviving women was $9.8 \pm 10.8$ days.
No significant difference in clinical characteristics was observed between patients who between patients who survived and those who died after the procedure except for indication of hysterectomy. Most of mortality cases $(31 / 48,64.6 \%)$ were due to uterine atony after delivery outside the hospital (Table 2).

In the cases who survived, the average preoperative hemoglobin level was $7.15 \pm 2.41 \mathrm{~g} / \mathrm{dL}$, and the postoperative hemoglobin level was $9.64 \pm 1.69 \mathrm{~g} / \mathrm{dL}$. An average of $10.4 \pm 6.9$ units of blood products was transfused. In mortality cases, the average preoperative hemoglobin level was $5.92 \pm 2.11 \mathrm{~g} / \mathrm{dL}$, and the postoperative hemoglobin level was $7.22 \pm 1.13 \mathrm{~g} / \mathrm{dL}$. An average of $14.9 \pm 11.7$ units of blood products was transfused. There was a significant difference between 
both groups in the amount of transfused blood products (Table 2).

The intraoperative and postoperative complications are shown in Table 3. There were $26(21.1 \%)$ cases of intraoperative bladder injury. Twenty of these patients had previously scarred uterus and the current pregnancy was complicated with morbidly adherent placenta. Accidental ureteric ligation was present in $2(1.6 \%)$ cases.

Table 3: Intraoperative, postoperative complications and maternal outcomes of emergency peripartum hysterectomy cases.

\begin{tabular}{|ll|}
\hline Characteristics * & $(\mathbf{n}=123)$ \\
\hline Bladder injury & $26(21.13)$ \\
\hline Ureteric ligation & $2(1.63)$ \\
\hline Re-exploration & $11(8.94)$ \\
\hline DIC & $11(8.94)$ \\
\hline Pulmonary embolism & $5(4.07)$ \\
\hline ARDS & $4(3.25)$ \\
\hline Acute Renal Failure & $3(2.44)$ \\
\hline Multi-organ failure & $3(2.44)$ \\
\hline $\begin{array}{l}\text { Dehiscence and wound } \\
\text { infection }\end{array}$ & $3(2.44)$ \\
\hline Maternal mortality & $48(39.02)$ \\
\hline ICU admission & $74(60.16)$ \\
\hline *Data presented as number $\quad(\%) ;$ DIC: disseminated \\
$\begin{array}{l}\text { intravascular coagulopathy; ARDS: acute respiratory distress } \\
\text { syndrome; ICU: intensive care unit. }\end{array}$ \\
\hline
\end{tabular}

Table 4: Multivariate logistic regression analysis for risk factors of maternal mortality in emergency peripartum hysterectomy cases.

\begin{tabular}{|llll|}
\hline Variables & p-value & $\begin{array}{l}\text { Odds } \\
\text { ratio }\end{array}$ & $95 \%$ CI \\
\hline $\begin{array}{l}\text { Age } \geq 40 \\
\text { years }\end{array}$ & 0.000 & 5.49 & $\begin{array}{l}2.16- \\
13.96\end{array}$ \\
\hline Gravidity & 0.10 & 1.13 & $0.98-$ \\
& & & 1.30 \\
\hline Parity $\geq 5$ & 0.009 & 0.34 & $0.15-$ \\
& & & 0.77 \\
\hline $\begin{array}{l}\text { Gestational } \\
\text { age at delivery }\end{array}$ & 0.60 & 1.03 & $0.92-$ \\
\hline $\begin{array}{l}\text { Mode of } \\
\text { delivery }\end{array}$ & 0.38 & 0.73 & $0.35-$ \\
\hline $\begin{array}{l}\text { Type of } \\
\text { hysterectomy }\end{array}$ & 0.61 & 0.83 & $0.39-$ \\
\hline Uterine atony & 0.90 & 0.90 & 1.73 \\
\hline & & & $0.17-$ \\
\hline Rupture uterus & 0.38 & 2.25 & $0.37-$ \\
\hline $\begin{array}{l}\text { Hb level } \\
\text { before surgery }\end{array}$ & 0.13 & 1.51 & $0.88-$ \\
\hline $\begin{array}{l}\text { Blood } \\
\text { transfusion }\end{array}$ & 0.13 & 1.10 & $0.97-$ \\
\hline
\end{tabular}

Hb: hemoglobin; CI: confidence interval
The mean duration of postoperative hospitalization stay was $8.8 \pm 5.7$ days. Seventy four $(60.2 \%)$ cases were admitted to intensive care unit. Postoperative complications occurred in $37(30.1 \%)$ patients. There were 11 patients $(8.90 \%)$ who required a return to the OR after surgery to manage intra-abdominal bleeding.

In the current study, using multivariate logistic regression analysis, we found that woman's age $\geq 40$ years and parity $\geq 5$ were the most significant independent predictors for maternal mortality in cases of EPH (OR $5.49 ; 95 \%$ CI 2.16 - 13.96) and (OR 0.34; 95\% CI 0.15 0.77 ) respectively (Table 4 ).

\section{DISCUSSION}

In the current study, the incidence of emergency peripartum hysterectomy from the year 2009 to 2014 was 1.30 per 1000 delivery. Uterine atony was the main indication of EPH in our institution in Upper Egypt.

EPH remains a lifesaving procedure especially in women with severe uncontrollable PPH. ${ }^{16}$ The first successful obstetric hysterectomy was carried out in 1876 by Eduardo Porro from Italy ${ }^{17}$ and it was used to prevent maternal mortality from PPH. Before this first successful $\mathrm{EPH}$, classic CS was associated with nearly $100 \%$ maternal mortality. ${ }^{18}$

Currently, the incidence of EPH is reportedly rising all over the world. In the current study, we found that the incidence of EPH in our hospital was 1.30 per 1000 delivery. This incidence was lower than the previous studies reported from Egypt as Allam et $\mathrm{al}^{14}$, who found the incidence between 2003 and 2008 was 2.24 per 1000 delivery. Mesbah et $\mathrm{al}^{15}$ in their study from 2008 to 2011 reported the incidence of EPH was 2.9 per 1000 delivery. However, this incidence is still higher than reports from developed countries. In European countries; a rate of 0.2 per 1000 births was reported from Norway ${ }^{20}$, and 0.3 per 1000 births from Netherlands. ${ }^{7}$ Effective antenatal care, hospital facilities and low parity among European population are the major causes.

The most frequent indication for EPH in our study was postpartum hemorrhage due to uterine atony (60/123) followed by morbidly adherent placenta (27/123). This is consistent with similar study performed in Republic of Korea in where uterine atony was the most common cause of EPH. ${ }^{20}$ Korejo et $\mathrm{al}^{21}$ and Obiechina et $\mathrm{al}^{22}$ reported in their studies that uterine rupture was the major indication of EPH, while Karaylcin et $\mathrm{al}^{23}$ and Allam et $\mathrm{al}^{14}$ reported that abnormal placentation was the most common indication of EPH.

Risk factors for EPH include multiparity, previous CS, low socioeconomic class and unbooked status. ${ }^{24}$ This was consistent with our results as multiparity was observed in $96.75 \%$ of cases. The parity-related increase is explained by its association with placenta previa, high liability of 
rupture uterus during delivery and higher incidence of uterine atony after delivery. Also $55.28 \%$ of women had a history of previous CS. All cases of EPH (27 cases) due to morbidly adherent placenta was associated with a history of repeated CS. Allam et $\mathrm{al}^{14}$ reported in their study that $63.1 \%$ of women who underwent EPH had a past history of previous CS. This coincided nearly with our results.

Cesarean delivery also is a well-known risk factor for EPH. ${ }^{10}$ In our study, $58.54 \%$ of EPH cases were carried out in women who delivered by CS. This rate is lower than reported by Allam et al ${ }^{14}$ study in which $74.4 \%$ of EPH cases were delivered by CS.

Similarly, Kwee et al and Whiteman et $\mathrm{al}^{7,25}$ found that both previous CS and current cesarean delivery were associated with an increased risk for EPH, especially for those who had a repeat CS.

It is well known that EPH is usually associated with extensive blood loss which necessitates a higher number of blood transfusions. ${ }^{26}$ This was clear in our study; an average of $14.9 \pm 11.7$ units of blood products was transfused to mortality cases and $10.4 \pm 6.9$ units for survivors. The significant difference in the amount of transfused blood between both groups is related to the severity of hemorrhage and hemodynamic instability.

Supracervical hysterectomy was the commonly performed procedure in our study (71/123) as consistent with previous studies. ${ }^{14,15,27}$ It is relatively easier and takes less time to control the hemorrhage in hemodynamically unstable patients. In spite of that, total hysterectomy was performed in 52 cases, most of them presented by morbid adherent placenta or rupture uterus with extended cervical or vaginal lacerations.

$\mathrm{EPH}$ in the current study was associated with high maternal morbidity. This is consistent with previous studies. $^{15}$ Re-exploration was performed in 11 cases $(8.9 \%)$. This rate is lower than reported by Begum et $\mathrm{al}^{28}$ which was $15 \%$. DIC was the major contributing factor that stimulates the re-exploration. The most common complication found was intraoperative bladder injury in $21.13 \%$ of cases. This is rate is high but nearly similar to Awan et $\mathrm{al}^{29}$ results who reported $22.6 \%$ of intraoperative urinary tract injuries in their series. A planned rather than an emergency caesarean hysterectomy in women at high risk of EPH may be associated with lower morbidity rates.

There were 48 cases $(39.02 \%)$ of maternal mortality in our study, which is very high rate if compared with developed countries. ${ }^{30}$ This may be attributed to the delay in arrival of most of patients to our hospital from discrete and rural areas. Also, the delay in taking decision of EPH in near-miss cases until failure of all conservative trials to stop bleeding was a major contributor in this high rate, as hysterectomy is not accepted easily by patient's relatives especially in low parity or young women. EPH in young women not only leads to high morbidity, but also has serious psychological and social implications, especially when their parity is low. In spite of the cultural background in Egypt that prefers large families is a considerable factor, timing of EPH is critical to achieve an optimal outcome and decrease maternal deaths as it should not carried out too early or too late.

In the current study, age $\geq 40$ years and parity $\geq 5$ were the most significant variables associated with maternal mortality in cases of EPH. In spite of the decision of hysterectomy was taken rapidly in such cases, but the false sense of security in labor due to previous experience of repeated deliveries and the substandard nutrition in our community leads to more mortality in those women. Our policy in management of this high risk group should be changed by increasing the community awareness about the family planning services to prevent any unwanted pregnancy, providing regular antenatal care with correction of anemia before delivery and finally their delivery should be in health facilities with good resources to prevent $\mathrm{PPH}$.

\section{CONCLUSION}

In conclusion, there is still a high incidence of EPH in Egypt as a developing country with significant high maternal mortality. Early referral and rapid decisions to perform EPH may save patients' lives and prevent maternal complications. Further audit studies of EPH cases in our hospital is needed to identify the major contributing factors to this procedure.

The limitations of the current study is related to being retrospective, certain information about the patients were missed in their records as educational level, socioeconomic status and booking status. These factors can contribute significantly in the rate of EPH and consequent maternal mortality. Data about neonatal outcome were also poorly documented. This limited our analysis to the available information.

\section{Funding: Not required \\ Conflict of interest: None declared \\ Ethical approval: The study was approved by the Institutional Ethics Committee}

\section{REFERENCES}

1. Knight $\mathrm{M}$, Callaghan WM, Berg C, Alexander S, Bouvier-Colle $\mathrm{MH}$, Ford JB, et al. Trends in postpartum hemorrhage in high resource countries: a review and recommendations from the International Postpartum Hemorrhage Collaborative Group. BMC Pregnancy Childbirth. 2009;9:55.

2. Forna F, Miles AM, Jamieson DJ. Emergency peripartum hysterectomy: a comparison of cesarean and postpartum hysterectomy. Am J Obstet Gynecol. 2004;190:1440-4. 
3. Ali MK, Badee AY, Abbas AM, Shazly SA. A novel technique for modified B-Lynch suture for the control of atonic postpartum haemorrhage. Aust N Z J Obstet Gynaecol. 2013;53:94-7.

4. Flood KM, Said S, Geary M, Robson M, Fitzpatrick $\mathrm{C}$, Malone FD. Changing trends in peripartum hysterectomy over the last 4 decades. Am J Obstet Gynecol. 2009;200:632 e1-6.

5. Bodelon C, Bernabe-Ortiz A, Schiff MA, Reed SD. Factors associated with peripartum hysterectomy. Obstet Gynecol. 2009;114:115-23.

6. Zeteroglu S, Ustun Y, Engin-Ustun Y, Sahin G, Kamaci M. Peripartum hysterectomy in a teaching hospital in the eastern region of Turkey. Eur J Obstet Gynecol Reprod Biol. 2005;120:57-62.

7. Kwee A, Bots ML, Visser GH, Bruinse HW. Emergency peripartum hysterectomy: a prospective study in the Netherlands. Eur J Obstet Gynecol Reprod Biol. 2006;124:187-92.

8. Sakse A, Weber T, Nickelsen C, Secher NJ. Peripartum hysterectomy in Denmark 1995-2004. Acta Obstet Gynecol. 2007;86:1472-75.

9. Chestnut DH, Eden RD, Gall SA, Parker RT. Peripartum hysterectomy: a review of cesarean and postpartum hysterectomy. Obstet Gynecol. 1985;65:365-70.

10. Stanco LM, Schrimmer DB, Paul RH, Mishell DR Jr. Emergency peripartum hysterectomy and associated risk factors. Am J Obstet Gynecol. 1993;168:879-83.

11. Daskalakis G, Anastasakis E, Papantoniou N, Mesogitis S, Theodora M, Antsaklis A. Emergency obstetric hysterectomy. Acta Obstet Gynecol Scand. 2007;86:223-7.

12. Kastner ES. Figueroa R, Garry D, Maulik D. Emergency peripartum hysterectomy: experience at a community teaching hospital. Obstet Gynecol. 2002;99:971-5.

13. Yucel O, Ozdemir I, Yucel N, Somunkiran A. Emergency peripartum hysterectomy: a 9-year review. Arch Gynecol Obstet. 2006;274:84-7.

14. Allam IS, Gomaa IA, Fathi HM, Sukkar GF. Incidence of emergency peripartum hysterectomy in Ain-shams University Maternity Hospital, Egypt: a retrospective study. Arch Gynecol Obstet. 2014;290:891-6.

15. Mesbah Y, Ragab A, Fialla E, Barakat R, Badawy A, Ragab Ahmed. Emergency peripartum hysterectomy: the experience of a tertiary referral hospital. Middle East Fertility Soc J. 2013;18:89-93.

16. Shellhaas CS, Gilbert S, Landon MB, et al. The frequency and complication rates of hysterectomy accompanying cesarean delivery. Obstet Gynecol. 2009;114:224-9.

17. Sing A, Hada M, Yangzom K, Anita GC. Emergency peripartum hysterectomy. N J Obstet Gynaecol. 2006;1:33-6.
18. Imudia AN, Hobson DT, Awonuga AO, Diamond MP, Bahado-Singh RO. Determinants and complications of emergent cesarean hysterectomy: supracervical vs total hysterectomy. Am J Obstet Gynecol. 2010;203:221.e1-5.

19. Engelson IB, Albrechsen S, Iversen OF. Peripartum hysterectomy: incidence and maternal morbidity. Acta Obstet Gynecol Scand. 2001;80:409-12.

20. Bai SW, Lee HJ, Cho JS, Park YW, Kim SK, Park $\mathrm{KH}$. Peripartum hysterectomy and associated factors. J Reprod Med. 2003;48:148-52.

21. Korejo R, Jafarey SN. Obstetrics hysterectomy-five years' experience at Jinnah Postgraduate Medical Centre, Karachi. J Pak Med Assoc. 1995;45:86-8.

22. Obiechina NJ, Eleje GU, Ezebialu IU, Okeke CA, Mbamara SU. Emergency peripartum hysterectomy in Nnewi, Nigeria: a 10-years review. Niger J Clin Pract. 2012;15:168-71.

23. Karayalcin R, Ozcan S, Ozyer S, Mollamahmutoglu L, Danisman N. Emergency peripartum hysterectomy. Arch Gynecol Obstet. 2011;283:7237.

24. Imudia AN, Awonuga AO, Dbouk $\mathrm{T}$, Kumar $\mathrm{S}$, Cordoba MI, Diamond MP, et al. Incidence, trends, risk factors, indications for, and complications associated with cesarean hysterectomy: a 17-year experience from a single institution. Arch Gynecol Obstet. 2009;280:619-23.

25. Whiteman MK, Kuklina E, Hillis SD, Jamieson DJ, Meikle SF, Posner SF, et al. Incidence and determinants of peripartum hysterectomy. Obstet Gynecol. 2006;108:1486-92.

26. Mahmood S, Ayaz A. Obstetrical hysterectomy. J Sur Pak. 2005;10:20-3.

27. Anita K, Kavita W. Emergency peripartum hysterectomy. J Obstet Gynaecol India. 2005;55:1324.

28. Begum M, Alsafi F, ElFarra J, Tamim HM, Le T. Emergency peripartum hysterectomy in a tertiary care hospital in saudia Arabia. J Obstet Gynaecol India. 2014;64:321-7.

29. Awan N, Bennett MJ, Walters WA. Emergency peripartum hysterectomy: a 10-year review at the Royal hospital for women, Sydney. Aust N Z J Obstet Gynaecol. 2011;51:210-5.

30. Knight M, Ukoss M. Peripartum hysterectomy in the UK: management and outcomes of the associated hemorrhage. BJOG. 2007;114:1380-7.

Cite this article as: Abbas AM, Abdelbadee AY, Amin MT, Abdelrahman RM, Tolba SM, Abdelkarim AR, et al. Emergency peripartum hysterectomy in a tertiary hospital in Upper Egypt: six years analysis. Int J Reprod Contracept Obstet Gynecol 2016;5:953-8. 